\title{
Sinus Pain, CTCAE 5.0
}

National Cancer Institute

\section{Source}

National Cancer Institute. Sinus Pain, CT CAE 5.0. NCI Thesaurus. Code C146783.

A disorder characterized by a sensation of marked discomfort in the face, between the eyes, or upper teeth originating from the sinuses. 